\title{
El BLOG DE COMENTARIOS A TEXTOS DE OPINIÓN \\ EN CIBERPERIÓDICOS: UN GÉNERO EN CONSTANTE RECONSTRUCCIÓN ${ }^{*}$
}

\author{
María Cristina Arancibia Aguilera ${ }^{* *}$ \\ Lésmer Antonio Montecino Soto
}

\section{Resumen}

Este artículo tiene como objetivo presentar un estado de la cuestión acerca del género discursivo blog, utilizado para comentar columnas de opinión y editoriales publicados en ciberperiódicos chilenos. En la actualidad, el ciberciudadano constituye el foco de interés de un número, cada vez más creciente, de medios de comunicación masivos en línea, también llamados "ciberperiódicos". Muchos de estos abren sitios de participación para sus lectores a través de blogs, invitándolos a hacer públicas sus opiniones respecto del contenido de editoriales, columnas de opinión y noticias. En este contexto, nos llama poderosamente la atención la naturaleza de los comentarios que generan las columnas de opinión y editoriales. El blogueo de comentarios ha permitido la reemergencia de la democracia deliberativa, entendida como el intercambio de ideas, acompañada por la discusión sustantiva de temas actuales en un contexto de respeto mutuo. A través de una revisión de estudios recientes que incluyen investigaciones realizadas en los últimos siete años, se pretende definir y caracterizar el blog de comentarios de ciberperiódicos en términos de sus condiciones de producción, estructura discursiva y textual, para luego concluir con una mirada respecto del propósito social de esta práctica.

Palabras clave: ciberperiódicos, blogs, género, comentario, comunidad discursiva, participación cívica

\section{BLOG COMMENTS TO OPINION ARTICLES: A GENRE IN CONSTANT RECONSTRUCTION}

\begin{abstract}
The objective of this article is to provide an overview of the genre of online blogs to comment on opinion columns and editorials published in Chilean ciber newspapers. At present, the ciber citizen is the focus of interest of an increasing number of mainstream means of communication. Many of them provide bloggers with access to post their comments on blogs, inviting the public to express their views on the content of editorials, opinion columns and news stories. In this context, it seems intriguing the nature of comments generated by editorials and opinion columns. Online paper blogging has allowed for the re-emergence of deliberative democracy understood as the exchange of views about contingent issues in a context of relative mutual respect. Through a revisión of recent research that include studies

* Los contenidos de este artículo se enmarcan en el proyecto FONDECYT No 1120784: Representaciones discursivas sobre la pobreza en ciberperiódicos chilenos". Pontificia Universidad Católica de Chile

* Chilena, Doctora en Lingüística, Académica de la Facultad de Letras, Pontificia Universidad Católica de Chile, Santiago, Chile. marancag@uc.cl

*** Chileno, Doctor en Filosofía y Letras, Universidad de Valladolid, Académico de la Facultad de Letras, Pontificia Universidad Católica de Chile, Santiago, Chile. lmontecs@uc.cl
\end{abstract}


conducted in the last seven years, the purpose of this article is to define and characterize the commentary blogs in online cyber-newspapers in terms of their conditions of production, discourse and textual structure to finally provide an overview of the social purpose that the blogs of commentaries have as a social practice

Key words: cibe-newspapers, blogs, genre, commentary, discourse community, civic participation

\section{Introducción}

El ciberespacio ha dado origen a nuevas formas de comportamiento comunicativo que trascienden el escenario del individuo que enfrenta a su audiencia cara a cara o que escribe desde el solipsismo más absoluto. En este espacio virtual, el cibernauta espera ser leído e interpelado por otros sujetos, no obstante, cabe la posibilidad de que nadie lo lea o interactúe con él, hecho que nunca sabremos cuánto le afecta.

El soporte digital tiene como contraparte un formato tradicional que permite el estudio del discurso oral y escrito, materializado en papel, audio o videograbación, como señalan Kwasnick y Crowston (2005) y Santaella (2010). Lo digital subvierte lo estatuido a través del hipertexto, cuyo rol parece complejo para los géneros mediados por la Web, puesto que no solo apuntan a centrarse en el contenido del discurso, sino que implican atender a cómo se accede a estos. Hablar de hipertextualidad, supone tomar contacto con una forma de comunicación, fruto de un proceso selectivo de rutas de navegación que constituyen la sociedad multimedial. Aun cuando, como lectores, ponemos énfasis en el recorrido de lectura no lineal, caracterizada por la ausencia de centro común, lo singular es que se incluya la no linealidad y la construcción de sentido, tomando como base la interacción profunda de los diversos lenguajes que lo constituyen (Santaella, 2010; San Martín, 2003; Landow, 1997). Al respecto, Edo (2009: 32) señala: “El hipertexto no es secuencial, no responde a las claves tradicionales de la lectura, sino que se apoya en la capacidad de la mente humana para relacionar ideas, hechos y datos diferentes".

Dentro del ciberespacio gravita un número importante de cibergéneros (González, 2012; Yus, 2010) mediados por computador tales como el chat,

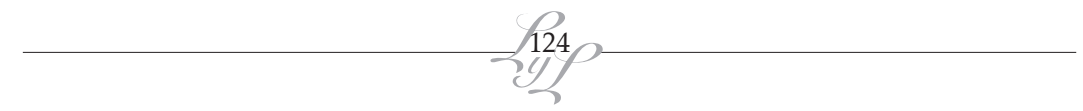


los sitios Web, el Twitter, el Facebook, los blogs y otros, que conforman lugares de reunión de ciudadanos cuyo símil es el café de una anónima esquina o la plaza pública según sea el caso (Moita Lopes, 2010; Mitchell, 1995; Bajtin, 1990). En este contexto, la blogósfera no puede estimarse menos importante que otras esferas interactivas, a pesar de su naturaleza asincrónica, puesto que ha evolucionado desde el Weblog personal hasta el blog de comentarios. Su existencia, en un entorno donde la inmediatez controla la comunicación entre usuarios, no ha sido amenazada en su continuidad, persistiendo, de este modo, como un espacio donde se reinventaría la vida social y política de la comunidad de usuarios y, en proyección más extensa, la del país. Así, Flores (2009), refiriéndose a los nuevos modelos de comunicación que se generan en las redes sociales, afirma que la Internet es la red social por antonomasia, aunque, en rigor, no debe considerarse en sí una red social, sino una plataforma cuyos recursos generan nuevas formas de entender la comunicación como un entramado de relaciones sociales que opera en un espacio virtual. Este espacio irreal e inexistente (Fraca, 2006), en términos físicos, es un lugar de encuentros de amigos y de reunión de personas con intereses comunes que configuran comunidades discursivas y ciberempresas.

Las ciberempresas de medios de comunicación masiva o emporios mediáticos, como las denomina Flores (2009), adhieren al uso de tecnologías interactivas ante el riesgo de ser desplazadas por las redes sociales, donde los individuos ejercen su libertad de expresión alejados de la hegemonía del cuarto poder (Varela, 2005), cuyo discurso dominante ha prevalecido por décadas, pero que hoy ve en el éxito de las redes sociales, la urgencia de ser, a través del blog, parte de ellas.

En consecuencia, el ciberciudadano constituye el foco de interés de un número cada vez más creciente de empresas de medios de comunicación masivos en línea o "ciberperiódicos". Estos abren sitios de participación a través de blogs, invitando a los lectores a hacer públicas sus opiniones frente a editoriales, columnas de opinión y noticias. En este contexto, llama poderosamente la atención la naturaleza de los comentarios que generan las columnas de opinión y editoriales, puesto que el blogueo de comentarios ha permitido, según Komesu (2010) y Koch (2005), la reemergencia de la democracia deliberativa, entendida como el intercambio de ideas, acompañada por la discusión sustantiva de temas actuales en un contexto ideal de respeto mutuo. 
El comentario de blog constituye un tipo de discurso que trasciende su formulación y se realiza ${ }^{4}$ en acciones discursivas que transforman, renuevan, reanudan, y/o deconstruyen la acción discursiva de origen. El comentario a columnas de opinión y editoriales puede entenderse como "la construcción de una relación discursiva sujeta a continua modificación, que en su raíz más profunda, constituye la enunciación de lo articulado en silencio por otros lectores y que se expresa por primera y única vez cuando se enuncia" (Foucault, 2002: 29). En el comentario coinciden, contrapuestas, renovación y repetición, es decir, en él se encuentran actos discursivos nuevos que reanudan y/o transforman el acto discursivo original. Esta especie de repetición renovada que aparece tan claramente articulada en el comentario, es una de las características fundamentales del género, lo que le permite deconstruir, recrear y crear indefinidamente visiones de mundo.

De acuerdo con lo expuesto, el propósito de este artículo consiste en describir el status quaestionis de los estudios del género discursivo blog en el contexto de comunicación establecido para los comentarios que se postean en ciberperiódicos chilenos. Con este objetivo, se presentará primero una definición y caracterización general del blog; en segundo lugar, se aborda el impacto político que ha tenido la blogósfera en las prácticas discursivas del ciberciudadano, y finalmente, se entrega una visión del género producto de una observación de diversos blogs de comentarios extraídos de los portales de ciberperiódicos nacionales, tales como EMOL, EL MOSTRADOR y THE CLINIC, revisados entre marzo y octubre de 2012 .

\section{Caracterización del blog en la actualidad}

En la actualidad, el discurso mediado por computador (Sanz, 2012; Boicu, 2011; Yus, 2010; Fraca, 2006; Koch, 2005; Hlavach \& Freivogel, 2005; Crystal, 2002), ocupa un lugar importante en los estudios de género ligados a medios de comunicación masiva como es la prensa digital. El blog, se define como un espacio posibilitador de la comunicación en línea, que se

4 La realización de un comentario de blog implica codificar desde los niveles más abstractos del lenguaje hasta los niveles más concretos. En otros términos, se trata de potenciales instanciaciones que suponen la actualización paulatina del potencial de significado que alcanza su grado máximo de visibilización en un texto o instancia (Halliday \& Matthiessen, 2006). En nuestro caso, el comentario de blog se materializa en un texto concreto, cuyas opciones léxico-gramaticales, según la Lingüística Sistémico Funcional, construyen un significado instanciado. 
encuentra relacionado con otros medios de intercambio de información instantánea como son la página Web, el correo electrónico y el chat, entre otros. Herring, Scheidt, Wright y Bonus (2007) sitúan el blog en un espacio intermedio entre el sitio Web y el correo electrónico, ambos definidos como medios de contacto asincrónicos que permiten el envío de mensajes, dando al usuario cierta libertad respecto de los tiempos de respuesta.

Estudios realizados con usuarios de blogs (Boicu, 2011; Gil de Zúñiga, Puig-Abril, Rojas, 2009; Herring et al., 2004), muestran que este tipo de discurso se percibe como un medio de comunicación flexible, puesto que permite el posteo de comentarios sin límite de tiempo, facilitando la ocurrencia de mayor interacción que en el caso del sitio Web, dado que ofrece la posibilidad de una actualización periódica o continua. El blog es un singular modo de expresión que tiene por objetivo promover la cooperación -voluntaria, asincrónica y pública- de los participantes en la ciberinteracción. Esta modalidad comunicativa realizada entre el blogger y el internauta se concibe como un proceso de comunicación sin límites demarcados, que se ha consolidado como alternativa al paradigma tradicional de los medios de comunicación configurados desde una perspectiva jerárquica y unidireccional (Baynat, 2012). De este modo, el blog abre un espacio de discusión sobre asuntos considerados relevantes, para quienes se dan el tiempo de expresar sus puntos de vistas, trascendiendo de esta manera la cotidianeidad del chateo y la inmediatez del Twitter.

La facilidad de edición, actualización constante y mantención del blog lo hace ser considerado como uno de los principales factores para su éxito como herramienta de autoexpresión, reflexión e intercambio de opiniones, hecho que realza el sentido de comunidad que se construye en el intercambio de comentarios. Para Boicu (2011), los blogueros que coinciden en el mismo espacio e inician una interacción en torno a un tema común, constituyen una comunidad de práctica discursiva, situación que asemeja, a escala, la trama de relaciones que conforman el tejido discursivo de la sociedad.

La tecnología y los medios de comunicación se caracterizan por darse forma mutuamente; se constituyen en prácticas humanas sociotécnicas (Kleis, 2012). El autor argumenta que el blog de comentarios, a la luz de las prácticas sociotécnicas que conforman el nuevo contexto de comunicación, no conforman una tecnología particular, sino una 
configuración, un modo de uso y un conjunto de herramientas asociadas a las expectativas de sus usuarios, cuyas formas de acción se realizan a través de las propiedades tecnológicas del blog, que permiten el desarrollo de prácticas discursivas específicas en el espacio digital.

En el presente, la comunicación se realiza bajo un velo de anonimato relativo. Este supuesto ocultamiento de la identidad, no obstante, se encuentra plenamente ajustado al concepto de libertad de Rousseau, es decir, a un anonimato regulado por convenciones que forman la base del legítimo actuar en sociedad. En este espacio digital de libre expresión, prevalece la figura del policía discursivo (Foucault, 2002), quien como entidad omnipresente, domina las acciones discursivas nacidas al alero de la comunicación construida en línea. El rol del policía discursivo en el espacio digital, no es un papel que asume un solo individuo, sino la comunidad discursiva que, de acuerdo con Marcuschi y Xavier (2005), para cada género, sienta sus propias reglas reflejadas en el propósito social que va siendo visible al internauta a través del contexto comunicativo que se establezca para la producción y distribución del discurso.

La comunidad discursiva que nace al alero de la blogósfera regula sus actos discursivos de acuerdo con normas que legitiman e identifican a miembros que constituyen dicha comunidad. Es así, como BiasiRodrigues, Araujo y de Sousa (2009), señalan que los géneros discursivos al obedecer a propósitos sociales que se realizan en textos tipificados, sistematizan las acciones afectando derechos y deberes de las personas. En el contexto de lo señalado anteriormente, cabe destacar el peso moral que ejerce el sentirse miembro de una comunidad de práctica digital, puesto que, las interacciones que en su interior se producen, se ven tipificadas por reglas de etiqueta que en ningún momento han sido explicitadas y que, sin lugar a dudas, son aceptadas, respetadas y adoptadas en las prácticas discursivas que se observan en los blogs de los diferentes portales de noticias (Boicu, 2011; Yus, 2010; Kuntsman, 2010).

En concordancia con lo afirmado por Biasi-Rodrigues et al. (2009), los géneros tipifican las acciones, puesto que obedecen a una secuencia de eventos con características predecibles que normalizan las acciones discursivas. Dentro del blog de comentarios en periódicos en línea, encontramos espacios donde las prácticas discursivas obedecen a normas muy estrictas de formalidad en el uso del lenguaje, como es el caso del portal EMOL. Existen, no obstante, portales donde el grado de distancia 
social y solidaridad entre blogueros es más cercano, lo cual provoca el quiebre de la formalidad y abre un espacio para la violación de las reglas de cortesía, a través del uso de lenguaje procaz (Eggins, 1994; Pinilla, 2009; Yus, 2010).

Las participaciones disruptivas o procaces, según Fuentes (2009), se deben a que quienes postean sus participaciones muchas veces, al no ser conocidos personalmente por los lectores, serán identificados como actores discursivos, hecho que implica que su imagen de seres reales versus seres empíricos que profieren insultos no estará expuesta al juicio de quienes lean sus posteos. Asimismo, se encuentran portales de noticias cuya tendencia declarada es la sátira política, situación que da origen a un contexto en el que el desdoblamiento propio del sujeto real en actor discursivo, ni siquiera es necesario. Los blogueros de estos medios que promueven el subgénero de la sátira política recrean un espacio similar al de la plaza pública descrita por Bakhtin (1990). Este espacio habrá de servir para rescatar el espíritu carnavalesco que convive con el discurso oficial, cuyo propósito consiste en expresar, con absoluta libertad y desenfreno, la rabia, la impotencia y el malestar frente a un discurso hegemónico sacralizado que impone lo políticamente correcto a través del policía discursivo (Foucault, 2002). Lo anterior por medio de una selección léxica propia de un registro familiar y soez, caracterizado por insultos, referencias escatológicas, juramentos, fraseología y topoi populares, entre otros recursos discursivos.

Lo que lleva a los consorcios mediáticos a abrir espacios de participación a través de blogs de comentarios, es el temor a verse desplazados por el libre y fluido intercambio de información y opiniones que se da en las redes sociales (Moita Lopes, 2010; Farrel \& Drezner, 2008; Woodly, 2008). Los medios periodísticos, por muchas décadas controladores del discurso hegemónico, han sido testigos de la masiva convergencia de individuos en las redes sociales y, considerándose ellos mismos un medio social pionero en la congregación de audiencia, han decidido abordar la fuerte influencia de las redes sociales a través de la instauración de un nuevo modelo comunicativo que, precisamente, deje en el pasado el concepto de audiencia pasiva y rescate el concepto de comunidad discursiva (Varela, 2005).

El concepto subyacente al de audiencia, utilizado por más de tres décadas por los medios de comunicación social, establece una interacción 
unidireccional entre un receptor y un emisor; no obstante, la comunicación en la comunidad discursiva se caracteriza por una conexión constante entre sus miembros, quienes reciben mensajes a nivel centralizado y no personalizados lo que permite un diálogo de todos con todos (Kuntsman, 2010; Farrel \& Drezner, 2008). De este modo, podemos aseverar que en la actualidad, el modelo de comunicación emisor-receptor se encuentra desfasado por la manera en como se gesta la comunicación en los blogs de comentarios.

Los blogs poseen una estructura que permite observar el desarrollo de un tema por varios participantes, su disposición de manera similar al de una cascada se asemejaría al diálogo cara a cara en el que los interactuantes toman turnos, debatiendo en torno a un tema. Además, el blog, a diferencia de redes como Twitter, no tiene un límite de palabras, situación que confiere al bloguero libertad para desarrollar una reflexión de manera aún más completa que si estuviese en un contexto real de debate. Asimismo, una práctica constante en portales de ciberperiódicos es la exigencia que se impone al ciberlector de inscribirse como usuario. Esta medida puede entenderse como el ejercicio de control sobre el contenido que los blogueros de editoriales y columnas de opinión vierten en los espacios que el ciberperiódico les brinda para la expresión de sus comentarios.

La interacción en blogs se encuentra mediada por una cantidad de voces que muchas veces, dependiendo del tenor del texto editorial o la columna de opinión, oscila entre uno y más de ochocientas participaciones. Las voces presentes en los comentarios que se postean, muchas veces, son respuestas a otros posteos, situación que permite establecer un diálogo en el que participan abiertamente, tanto el usuario que oculta su identidad como aquel que no tiene problema en revelarla (Keren, 2010; Flores, 2009; Koch, 2005). Se genera, entonces, una sucesión de comentarios al comentario principal, sea este el texto editorial, la columna de opinión o la noticia.

Se puede afirmar, en términos generales, que el uso del blog como un espacio virtual individual en el que los cibernautas instalan su tema (recetas de cocina, viajes, decoración, etc.), ha ampliado su espectro de uso, al ser utilizado, en la actualidad, por los consorcios de comunicaciones que manejan diarios electrónicos con el afán de permitir la interacción a través de comentarios sobre política, cultura y sociedad (Edo, 2009). En ellos, se rescata una polifonía e intertextualidad que supone el ejercicio de

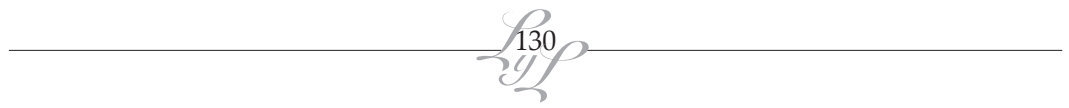


la democracia. El blog ha mutado de ser un espacio de creación individual, que invita a otros a participar en torno a un tema, a ser la plaza pública (Moita Lopes, 2010; Bajtin, 1990; Finol, 2005; Mitchell, 1995) que reúne a los ciberciudadanos para construir un espacio democrático donde cada uno se apropia de su voz y ya no la delega en sus candidatos (Mayol, 2012).

\section{Blog y participación cívica: impacto político de la blogósfera}

El blog es considerado por Woodly (2008) y Smith (2010), como una tecnología del conocimiento ampliamente utilizada en el área de la educación que comienza a ser usado por los medios de información tradicionales, políticos y profesionales, dando un giro a la agenda política que existe hasta el momento en Estados Unidos. En otros países en vías de desarrollo, ocurre un fenómeno similar, puesto que quienes tienen acceso a Internet son mayoritariamente profesionales y políticos. Estos emergen como una élite de opinión que influye de manera importante en el proceso de movilización política que se ha producido en todo el mundo. De este modo, el blog se concibe como una herramienta de participación cívica, cuyo propósito social y fases lo inscriben en la red de hipertextos, que permiten configurarlo como uno más de los tipos de textos dialogales mediados por el computador, cuyo fin, entre otros, apunta a fomentar una democracia deliberativa.

Flores (2009) instala la discusión acerca de la posible pérdida de influencia que el cuarto poder tiene sobre la sociedad actual y la adaptación que demanda sobre los consorcios informativos la expansión de la Internet. Cadenas informativas como CNN y BBC instalan plataformas de comunicación que mantienen al público, informado las 24 horas del día. Del mismo modo, la prensa escrita asume un formato electrónico, transformándose en lo que hoy se conoce como ciberperiódico (Yus, 2010; Edo, 2009). No obstante, el paso fundamental que transforma la escena política consiste en darle participación activa al ciudadano a través de plataformas sociales y blogs de comentarios.

Ante este nuevo escenario, la comunicación entendida como "nosotros enviamos, ellos reciben" (Flores, 2009: 78) queda obsoleta. Keren (2010) afirma que la interacción entre quienes postean sus comentarios genera un nuevo tipo de diálogo, puesto que la blogósfera abre un espacio para voces consideradas marginales en el discurso político; son las voces de 
personas que no votan por razones etarias o de conciencia. El blogueo, para Keren (2010), ha revitalizado la democracia. Los blogs permiten, a la comunidad que se reúne en torno a una columna de opinión o editorial, articular sus pensamientos, sentimientos, experiencias e identidades alejados del control hegemónico de los medios de comunicación de corriente principal.

La blogósfera permite que la discusión generada al interior de un ciberperiódico encienda el discurso cívico y sea una oportunidad de participación informal en la contigencia política, además de la instancia formal que constituye el voto en elecciones. Para Mayol (2012), Keren (2010), Woodly (2008) y Farrel y Drezner (2008), el discurso cívico decae, en parte, debido a una concepción de participación democrática que jamás contó con la enorme influencia de Internet.

Durante más de tres décadas, la participación cívica se entendió como la expresión de la voluntad política a través del voto. En la actualidad, y en especial desde 2011, la irrupción de grupos que se levantan en contra del sistema prevalente en Chile y en el mundo, parece indicar que el ciudadano ha recuperado la voz delegada en sus candidatos y asume la responsabilidad de expresar sus propias opiniones. En síntesis, el debate político se renueva en la blogósfera, al permitir al ciudadano común ser parte de este debate y cuestionar la voz de quienes, gozando de poder, tienen acceso a los medios de comunicación para expresar, desde ese estrado, su visión de los sucesos cotidianos. El blog de comentario es, en consecuencia, una herramienta de legitimación de la voz que ha permanecido en la marginalidad y cuya emergencia cuestiona la discusión política liderada únicamente por políticos (Flores, 2009; Keren, 2010; Mayol 2012).

Otra razón que explica el decaído interés en la participación cívica se debe a las rutinas de influencia que ejercen los medios masivos de comunicación, los cuales concentran sus esfuerzos en validar y diseminar la información y opiniones, manejadas por las fuentes oficiales de poder. De este modo, Woodly (2008) afirma, que se da una suerte de estructura hegemónica, cuyo objetivo es controlar las ideas que circulan en la sociedad de manera que el debate político adquiera un perfil que sirva al poder del Estado (Koch, 2005).

Junto al discurso hegemónico, existe otra rutina de influencia que, en lugar de centrarse en la hegemonía discursiva, posiciona su atención

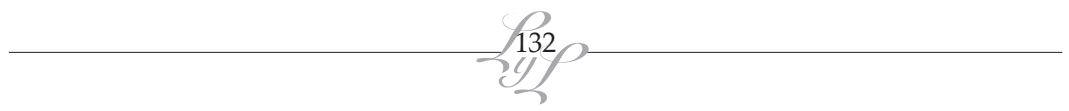


en el conflicto entre partidos políticos o corrientes de poderes opuestas, entre sí, con el objetivo de desviar la atención del público hacia contextos que se alejen de los reales problemas de contingencia. Cualquiera de las dos maneras de estructurar la realidad a través del discurso ocasiona creciente desazón entre los ciberciudadanos, puesto que la emergencia del discurso público se ve marginalizada por el dominio del discurso oficial, por una parte, y por el discurso a partir del conflicto, por otra. En este contexto, donde la mirada del ciudadano común y corriente se pierde, el blog emerge como un espacio que promueve la experiencia democrática, dando lugar a la constante reconstrucción de la intersubjetividad, a través de los comentarios, los que muchas veces aúnan y expresan la visión disidente que deconstruye tanto el discurso hegemónico como el discurso del conflicto, haciendo, entonces, visible el discurso de la exclusión.

\section{Hacia la configuración del género blog de comentarios}

El formato que hoy presentan los blogs, publicados en la amplia red de información que se maneja en Internet, se conoce desde 1996 y es ampliamente aplicado a partir de 1997. Los blogs son definidos como páginas Web frecuentemente actualizadas, cuyos posteos se organizan en una secuencia cronológica inversa. Esta herramienta digital es, en la actualidad, una de las formas de comunicación dominante en Internet. Herring et al. (2004) y Pinilla (2009) destacan el poder que alcanza el blog como una fuente alternativa de noticias y de emisión de opiniones, recordando el impacto que la caída de las Torres Gemelas había generado en la blogósfera, llegando a crearse un total de dos millones de blogs en Estados Unidos para comentar los sucesos políticos de 2001 y la subsecuente invasión a Iraq en 2003.

Se puede afirmar, además, que el blog es una herramienta flexible, puesto que puede ser adecuada a distintas necesidades. Para los periodistas, este constituye una fuente de información alternativa, mientras que, para los educadores y los empresarios, ha sido considerado como una herramienta de conocimiento. No obstante, para los blogueros que quieren compartir su cosmovisión con otros (Herring et al. 2004; Wei, 2009) el blog se constituye en un medio de autoexpresión y autoempoderamiento. 
Tecnológicamente, el blog se considera un puente entre documentos multimedia HTML y comunicación mediada por el computador en formato textual. De acuerdo con San Martín (2012), Yus (2010), Pinilla (2009) y Herring et al. (2004), el blog es un género híbrido que construye su esencia a partir de múltiples fuentes tales como la bitácora o cuaderno de registro de actividades y reflexiones en formato papel, la página Web, Twitter y otras herramientas digitales. En la actualidad se identifican tres tipos fundamentales de blog: aquellos que actúan como (1) filtros, (2) diarios personales y (3) cuadernos digitales. El contenido de los blog filtros, según Herring et al., es externo al bloguero, con links a noticias y otros eventos alrededor del mundo. En el caso de los diarios personales, estos contienen información enfocada en el autor del blog que puede consistir en el registro de sus hobbies o actividades cotidianas. Finalmente, los cuadernos digitales pueden contener información personal y vínculos externos que se caracterizan por la inclusión, por parte del bloguero, de ensayos extensos en torno a un tema específico.

En el caso concreto de los blogs de ciberperiódicos, su presencia ha reemplazado el tradicional concepto que los medios corporativos de comunicación sostuvieron desde su creación y que consistió en recoger, seleccionar y diseminar noticias que se difunden a los ciudadanos (Flores, 2009; Farrell \& Drezner, 2008). El ciberperiódico abre un espacio al público para que manifieste su comentario frente a editoriales y columnas de opinión, cuyo propósito social consiste en comentar hechos cotidianos de la contingencia política -o de otra índole- entretejiendo una red discursiva, cuyo objetivo es actuar de filtro (Wei, 2009), rompiendo con el discurso monológico de la información, para convertirse en una voz visible en el espacio virtual político.

Desde una perspectiva lingüística, Martin y Rose (2008), Halliday y Matthiessen, (2004) y Eggins (1994), definen el género como producto de procesos sociales orientados por un objetivo, que materializado en el texto, se estructura en movimientos discursivos que le dan su esencia. Lo anterior se puede observar en el siguiente ejemplo constituido por la columna que da origen a una serie de comentarios ${ }^{5}$.

5 Respetamos la ortografía original de los cibertextos. 
El Mostrador » Blogs y Opinión

Columnas

17 de julio de 2012

Hay lucro... ¿y qué?

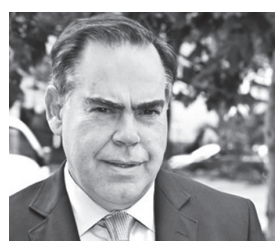

Álvaro Vial

Economista, director de empresas, socio de la agencia Acreditadora de Chile.

Acciones

Comentar

Enviar

Rectificar

Imprimir

La discusión que se desarrolla en estos momentos en torno a los temas de educación superior en el país, está plagada de ignorancia, mentiras, ideas fijas, caprichos y fijaciones, pero sobre todo de análisis absolutamente interesados y parciales que, en caso de llegar a concretarse en leyes, acabarían por hacer retroceder al sector a una época anterior a la década de los años ochenta.

Los tiempos no ayudan en nada, eso sí, a un análisis desapasionado, desprovisto de carga ideológica, más documentado y racional. Con los muchachos en la calle gritando a favor de la educación gratuita para todos y el escándalo producido por una universidad privada con sueldos académicos impagos, que prefiere destinar los pocos recursos existentes a retribuir a los dueños de la inmobiliaria, es difícil pedir algo más.

Irónicamente, sin embargo, los grandes males que, según la mayoría afectan a la educación superior chilena — universidades privadas, lucro y acreditación- son por lejos las principales causas del enorme progreso experimentado por este sector durante los últimos treinta años.

En 1980 Chile sólo tenía 8 universidades, con un total de 118 mil estudiantes. Solo el 7\% de los jóvenes de entre 18 y 24 años de edad podía estudiar en la universidad. La educación era gratuita. 
Sin embargo, la mayoría de los estudiantes provenía de familias de altos ingresos. El sociólogo brasileño Theotonio Dos Santos acostumbraba a empezar sus clases cada semestre preguntando al curso si había algún estudiante que fuera hijo de obrero. "Esta es la consecuencia del sistema capitalista", señalaba después de esperar sin éxito que alguien se levantara de su asiento.

El gobierno de Piñera debiera ayudar a resolver la confusión generalizada que existe actualmente respecto de este tema, evitando así que la incertidumbre reinante contribuya a paralizar el sector.

Dos Santos, como de costumbre, no estaba en lo correcto. Lo que había era consecuencia de un sistema cerrado, con escasa libertad económica, que impedía la participación de los privados y, en consecuencia, prohibía, en la práctica, a la mayoría de los jóvenes chilenos estudiar una carrera.

Si el profesor Dos Santos siguiera enseñando en Chile vería que hoy existen 59 universidades, 73 Centros de Formación Técnica (CFT), 45 Institutos Profesionales (IP) y más de un millón de estudiantes matriculados. Que siete de cada diez alumnos son primera generación en la universidad (y no "pijes" del barrio alto) y que a pesar de que se paga por la educación, ahora sí estudian hijos de obreros (el 51,8\% de los jóvenes en edad de estudiar una carrera lo puede hacer).

Fueron los privados, autorizados el año 1981 para crear universidades, IP y CFT, los que provocaron esta verdadera revolución. A partir de allí, el progreso no ha parado. De las 10 universidades que hoy reciben los mejores alumnos, 4 se crearon a partir del año 81 .

Lo anterior, que sería aplaudido en cualquier país del mundo, concentra en Chile la crítica ciudadana y genera marchas de estudiantes, discursos de repudio de diputados y senadores y comentarios ácidos de académicos. Los cientos de miles de estudiantes pobres que están en el sistema producen ahora un sentimiento de incomodidad difícil de explicar.

Los críticos quieren terminar con el lucro y ojalá estatizar la educación. Sería la mejor manera de retroceder en esta materia a los años setenta, cuando la educación superior, a pesar de ser gratuita, solo estaba permitida para los estudiantes de altos ingresos.

Los gobiernos de la Concertación, mostrando liderazgo y proyección, hicieron la vista gorda, durante 20 años, a la obtención de lucro en la educación superior, ayudando a los empresarios 
emergentes del sector a conseguir sus metas financiando a los alumnos de escasos ingresos.

El gobierno de Piñera debiera ayudar a resolver la confusión generalizada que existe actualmente respecto de este tema, evitando así que la incertidumbre reinante contribuya a paralizar el sector.

Ha llegado la hora de modificar la ley existente respecto del lucro. Si nos interesa hacer las cosas bien, deberíamos reconocer que el progreso que estamos comentando en el sector no se ha producido gracias a la ley, sino pese a ella. Ya es hora que dejemos a un lado por un minuto las payasadas y reconozcamos que los grandes artífices de este progreso fueron las nuevas universidades, algunas con lucro, otras sin lucro, y que ambos tipos de instituciones debieran sobrevivir.

128 Comentarios

Acciones

Comentar

Enviar

Rectificar

Imprimir

Disqus

Ingresar

Acerca de Disqus

Estamos contentos que te ha gustado. ¿Te gustaría compartirlo?

$\square$ Facebook

$\square$ Twitter

Compartir

No, gracias

Comparte esta página ...

Gracias! Close

Ingresar

Añadir Comentario

Escribir como ...

Mostrando 1-10 de 128 comentarios

Chamayo 1 comentario oculto Cerrar Expandir 
si es de la Agencia Acreditadora no puede hablar tanto a favor del lucro en la universidades privadas, creadas * $\sin$ fines de lucro* pero desde el tiempo de Pinochet QUE LUCRAN...Y HARTO QUE HAN LUCRADO....además no pagan IVA, ni pagan impuestos a la renta, no establecen los FUT entre sus socios, no pagan patentes comerciales, etc....Sr. Vial: Chile ya está informado ya que ni Pinochet, ni la Concertación y ni Piñera hablaron de este tema. Fueron los estudiantes (y familiares) que salieron a la calle a gritar esta verdad que era ocultada por los medios comunicacionales, por muchos políticos y parlamentarios, por la banca extranjera y nacional, etc. Pero si el capital de trabajo fue proporcionado por el Estado desde 1980, quiero decir, no han invertido NADA.-

Mostrar más Mostrar menos

A Me gusta

Responder

6 hace minutos

0 Me gusta

$\mathrm{F}$

Eugenio Bravo Eme 1 comentario oculto Cerrar Expandir

Sr. Vial... si usted dice que debe haber lucro en las universidades privadas chantas que polulan en este pobre Chilito, esquilmando a los muchachos de clase media baja y que además le ofrecen una educación cara y MEDIOCRE....entonces los lucradores deben pagar IMPUESTOS A LA RENTA COMO CUALQUIER CHILENO y no recibir dineros del Estado que van directo a sus billeteras....De este modo pueden lucrar las veces que deseen, pero PAGUEN LOS IMPUESTOS CORRESPONDIENTES.

Mostrar más Mostrar menos

A Me gusta

Responder

15 hace minutos

0 Me gusta

$\mathrm{F}$

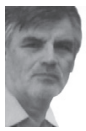

Pablo Gallo Arrieta 1 comentario oculto Cerrar Expandir

Felicito a Vial. El reconocer abiertamente que existe el lucro en la educación es meritorio y al revés de aquellos que se hacen los 
huevones o miran para el otro lado. Pero el discurso de Vial no es novedoso NO. Esta fracesita de justificar la creación de Ues. privadas para permitir el ingreso de los hijos de trabajadores y para respaldar el CAE, pertenece al inefable Ricardo Lagos Escobar, ex presidente de la República Bananera de Chile.

Pero pueden seguir mercantilizando la educación hasta que la ciudadanía de rienda suelta a la exacerbación de los espíritus y el sistema se les caiga a pedazos a la derecha económica y a los tránsfugas de la Concerta. Total, ya hemos juntado harta rabia los chilenos.

Mostrar más Mostrar menos

A Me gusta

Responder

34 hace minutos

1 Me gusta

F

\section{Acerca del comentario a columnas de opinión en ciberperiódicos}

En el caso del blog de comentarios que ilustra nuestras reflexiones acerca del género, este responde a una práctica social entendida como "decir por primera vez aquello que sin embargo había sido dicho" (Foucault, 2002: 15). El comentario para Foucault permite deconstruir y construir nuevos discursos, puesto que los comentarios que se agregan, reactualizan la información, pero, además, le proporcionan a su esencia el sentido múltiple que se da cuando un comentario genera nuevas ideas a partir del texto original. Foucault (2002:16) advierte también que "lo nuevo no está en lo que se dice, sino en el acontecimiento de su retorno". Esto último, entendido bajo la óptica de la retórica paralógica (Kent, 1994), implica entender la producción y recepción del discurso como una actividad hermenéutica, en la que cada individuo emplea su conocimiento de mundo y de la mente de los otros para interpretar el significado del mensaje que los interlocutores tratan de comunicar. De la misma manera, cada sujeto intenta descubrir el significado que otros darán a su mensaje.

A la luz de lo expuesto anteriormente, se puede observar que un blog de comentarios se iniciaría con un texto que simbólicamente corresponde 
al primer texto (Foucault, 2002: 15). La polifonía propia de cada enunciado (Bajtin, 1990) permite comprender que la columna de opinión es, en sí misma, un comentario (Edo, 2009) que involucra una cadena de otras voces materializadas en un texto escrito, columna de opinión que llamaremos primer texto. Este primer texto, tradicionalmente, comenta temas de contigencia nacional reciente, con títulos que capturan la atención del lector digital. La longitud de dichos textos varía entre 500 y 800 palabras. Estos textos son encabezados por sus respectivos títulos, el nombre del autor y una foto opcional de este. Los columnistas son enunciadores, cuyo discurso se encuentra legitimado por la relevancia que su participación tiene en la arena política, económica, educativa, tanto nacional como internacional.

En términos discursivos, las columnas de opinión tienen como finalidad definir la postura del autor respecto a la situación a la que hace referencia en su escrito. De este modo, los comentarios presentan evidencias del evento al que se refiere en el desarrollo de la columna. Dicha evidencia a menudo precede la aseveración con que la mayoría de los columnistas comienza su análisis, estableciéndose un procedimiento heurístico en el que el columnista recurre a la argumentación inductiva, basada en observaciones y validada a través del uso de cifras, ejemplos, analogías y la exposición de perspectivas ideológicas en comunión o disenso con el discurso hegemónico dominante.

La publicación de estas columnas de opinión en ciberperiódicos, considerados referentes informativos por el ciberciudadano que los sigue en la blogósfera, genera una cadena de respuestas a través del blog de comentarios. Este último, no sólo es un espacio digital para la opinión, sino que en algunos casos, se asemeja a un círculo de conversación con toma de turnos para contestar al columnista o a otro bloguero. Se da, incluso, el caso de blogs donde existe un bloguero que intenta liderar las conversaciones contestando a cada uno de los comentarios que se postean, con el fin de estimular la reflexión acerca del tema.

Es relevante destacar que el carácter argumentativo de las columnas de opinión, como asimismo el hecho de ser escritas por una élite intelectual, hacen que este tipo de género no sea asequible a un segmento amplio de la población, sino mayoritariamente a profesionales o a personas con un nivel de alfabetización que les permite contestar al columnista, esgrimiendo sus propios argumentos. Esto último nos lleva a observar la

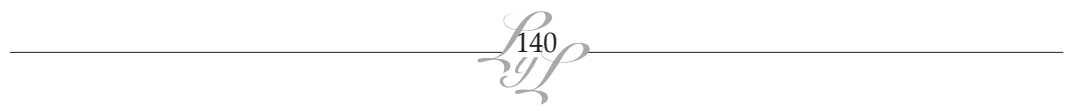


estructura discursiva interna del blog de comentarios, puesto que esta es reflejo del contexto situacional y del registro que realiza al posteo, según el medio digital en el que se prefiera opinar (Halliday y Matthiessen, 2004).

En general, los ciberperiódicos en los que se enfocó este estudio son medios digitales manejados por diferentes grupos corporativos y cuyas posturas políticas son igualmente distintas en cada uno de ellos. El portal EMOL representa el bastión conservador de la sociedad, con un declarado apoyo a la derecha más tradicional de Chile. EL MOSTRADOR es un medio digital abiertamente orientado hacia una posición más liberal y pluralista, mientras que THE CLINIC se asume como la visión insurrecta y carnavalesca que parte de la sociedad sostiene, respecto de la realidad económica, política y social del país. Cada una de las visiones a las que adhieren los ciberperiódicos revisados tiene claras repercusiones en las variables que construyen el registro y, en específico, en el tenor descriptor de la relación interpersonal entre quienes participan de esta conversación virtual.

En este contexto tenemos que tanto EMOL, EL MOSTRADOR y THE CLINIC exigen al bloguero estar inscrito en el portal. En el caso de EMOL y en los otros dos portales, el individuo debe pertenecer a una red social, llámese Twitter o Facebook. El espacio virtual para el comentario tiene en común, en la mayoría de los ciberperiódicos, la exhibición de la fecha del posteo. Las diferencias afloran al momento de revelar la identidad en cada portal. Se observa, por ejemplo, que en EMOL los posteos se publican con nombre y apellido del bloguero y no proporcionan espacio para la foto. En el caso de EL MOSTRADOR, se da la libertad al bloguero para publicar su nombre completo o bien identificarse a través de un pseudónimo; además, se proporciona un espacio para que éste publique su foto, si así lo desea. En THE CLINIC, lo primero que se observa es un espacio para la foto del bloguero, luego el nombre o pseudónimo y la fecha de publicación. Las diferencias señaladas pueden parecer triviales, no obstante, su impacto se ve expresado en los principios de estatus y solidaridad que subyacen en dichas interacciones virtuales.

De acuerdo con lo expuesto, la comunicación en línea, según nuestra observación de las interacciones en blogs de comentarios, queda a merced de lo impredecible y en absoluta imposibilidad de ser reducida a 
una descripción lógica que reduzca la comunicación a reglas normativas o enfoques gramaticales prescriptivos. Así, la comunicación en los blogs de comentarios debemos entenderla como un proceso hermenéutico dinámico y siempre emergente en el que sus participantes construyen redes de semiosis. Estas redes permiten co-construir significados de acuerdo con contextos específicos y un conocimiento de mundo compartido necesario para relevar determinadas representaciones en la mente de los otros, anticipando su interpretación. En otros términos, cada participante al explicitar una representación discursiva específica sabe o se aproxima al efecto contextual deseado.

\section{Consideraciones finales}

El ciberespacio ha dado vida a una nueva forma humana de comunicación que trasciende el escenario individual de la comunicación cara a cara. De este modo, el blog de comentarios emerge como un género híbrido, es decir, un texto escrito con la inestabilidad propia del lenguaje hablado. Asimismo, las distancias geográficas y temporales que separan a los blogueros implican una efímera situación comunicativa. Este carácter transitorio en el contexto del comentario a columnas de periódicos en línea, se vuelve un juego de permanencia y cambio que hace del mensaje enunciado, un acto discursivo siempre renovado en los comentarios que le siguen.

Los rasgos externos de un blog de comentarios suponen un espacio virtual en el que los comentarios se ordenan de manera temporal inversa; sin embargo, su disposición en línea continua, a manera de cascada, se puede asemejar al diálogo sincrónico entre interactuantes. Cabe señalar que el bloguero que ingresa a un determinado portal para comentar una columna, participa de una comunidad discursiva con normas socioculturales propias de cada endogrupo. Estas normas inclusivas o excluyentes, según el tipo de participación que el bloguero haya realizado -aditiva, cooperativa o disruptiva- se exteriorizan a través de tratamientos de cortesía y de una selección léxico-gramatical propia y relevante que impone un registro, acorde con los propósitos de la comunidad discursiva.

El ciberperiódico a través del blog de comentarios abre un espacio al público para que manifieste sus juicios frente a las columnas de opinión, construyendo una red de semiosis, cuyo objetivo consiste en romper con el discurso monológico, negociando los significados que 
se co-construyen a través del diálogo producto de las representaciones discursivas relevadas. Cabe destacar la naturaleza emergente del género blog de comentarios, en cuanto que constantemente está sujeto a modificaciones, según los propósitos sociales a los que sirve. Esto se condice con la perspectiva lingüística de Martin y Rose (2008), Halliday y Matthiessen, (2004) y Eggins (1994), para quienes el género es producto de procesos sociales orientados hacia un objetivo que, materializado en un texto, se estructura en movimientos discursivos que le dan su esencia en un contexto específico y siempre dinámico.

De acuerdo con lo observado en blogs de comentarios, las columnas de opinión definen la postura del autor respecto de un tema específico. Así, los comentarios que surgen son elaboraciones de juicios a favor o en contra que entregan evidenciassobrelo problematizadoen el textouno. El ciberciudadano que ingresa a la blogósfera genera un continuum de participaciones a través de sus comentarios, constituyendo un círculo de conversación similar al diálogo que se sostiene en una conversación cara a cara.

Cabe destacar el carácter argumentativo de las columnas de opinión, como asimismo el hecho de ser escritas por una élite intelectual que no solo entrega evidencias de su experiencia en el mundo, sino de su posición ideológica y política. De este modo, quienes interactúan en el blog de comentarios articulan sus juicios, expresan sus sentimientos, relatan sus experiencias y construyen sus identidades a través de narraciones personales que, antes de la emergencia de este género discursivo electrónico, habían sido consideradas marginales respecto del discurso político. En esta nueva fase de la comunicación política, los blogueros experimentan una suerte de liberación de los medios de comunicación de corriente principal, puesto que la información unilateral impuesta por los medios tradicionales, dificultaba la posibilidad de los ciudadanos de participar en deliberaciones públicas. El blogueo, en consecuencia, revitaliza la democracia en cuanto da voz a gran cantidad de ciberciudadanos que construyen una comunidad discursiva en la cual la expresión de las opiniones es universalmente valorada como ejercicio democrático, gracias a que la polifonía e intertextualidad instauran un sujeto dialogante. Para finalizar, el blog de comentarios ya no solo es un espacio de creación individual; los temas que se tratan suponen la participación de otros en esta especie de plaza pública 2.0, que reúne a los ciberciudadanos para configurar un espacio democrático donde cada uno asume su propia voz y prescinde de la mediación de sus candidatos en el ámbito político. 


\section{Referencias}

Bakhtin, M. (1990) La cultura popular en la Edad Media y el Renacimiento. Madrid, Alianza Universidad.

Bakhtin, M. (2008) Estética de la creación verbal, Buenos Aires, Siglo XXI.

Biasi-Rodrigues, B., Araújo, J.C, y Tavares de Soussa, S. C. (2009) genros textuais e comunidades discursivas: Um dialogo con John Swales. Belo Horizonte: Auténtica.

Boicu, R. (2011). Discursive norms in blogging. Romanian Journal of Journalism \& Communication, 6(1), 54-62.

Butt, D., Fahey, R., Feez, S., Spinks, S. Y Yallop, C. (2003). Using functional grammar: An explorer's guide. Macquarie University.

Crystal, D. (2002). Language and Internet [El lenguaje e Internet]. Madrid: Cambridge.

Edo, C. (2009). Periodismo informativo e interpretativo: El impacto de Internet en la noticia, las fuentes y los géneros. Sevilla: Comunicación Social Ediciones y Publicaciones.

Eggins, S. (1994). An introduction to systemic functional linguistics. London: Pinter.

Finol, J. (2005). Globalización, espacio, y ritualización: De la plaza pública al mall. Espacio Abierto, 14(4), 573-588

Foucault, M. (2002). L'ordre du discours [El orden del discurso]. Barcelona: Fabula.

Farrel, H., y Drezner, D. (2008). The power and politics of blogs. Public Choice, 134, 15-30.

Flores, M. (2009). Nuevos modelos de comunicación, perfiles y tendencias en las redes sociales. Comunicar, 33 (17), 73-81.

Fraca, L. (2006). La ciberlengua: Una variedad compleja de lengua en internet. Caracas: UPEL-IPC-IVILLAB.

Fuente, C. (2009). Cuando la descortesía se convierte en agresividad. Las listas de debate en el correo electrónico. En D. Bravo, N. Hernández y A. Cordisco (eds.) Aportes pragmáticos, sociopragmáticos y socioculturales a 
los estudios de la cortesía en español. Buenos Aires. Dunken.

Ghio, E., y Fernández, M. (2008). Lingüistica sistémico funcional: Aplicaciones a la lengua española. Santa Fe, Buenos Aires: Waldhuter.

Gil de Zuñiga, H,. Puig-I-Abril, E. Y Rojas, H. (2009). Webblogs, traditional sources online and political participation: An assessment of how the internet is changing the political environment. New Media E Society, 11(4), 553-574.

González, V. (2012). El discurso del turismo en Internet: Hacia una caracterización de sus géneros. En J. San Martín. Discurso turístico e Internet. Madrid: Iberoamericana Vervuert.

Goffman, E. (1967). Interaction ritual: Essays on face to face behaviour. Garden City, New York.

Halliday, M.A.K. (1985). An introduction to functional gramar. London: Arnold.

Halliday, M.A.K., y Matthiessen, C. (2004). An introduction to Functional gramar. London: Arnold.

Herring, S., Scheidt, L., Wright, E., y Bonus, S. (2004). Weblogs as a bridging genre. Information Technology \& People, 18(2), 142-171.

Hlavach, L., y Freivogel, W. (2011). Ethical implications of anonymous comments posted online news stories. Journal of Mass Media Ethics, 26, 21-37

Kent, T. (1994). Paralogic rhetoric: A theory of communicative interaction. Crambury, New Jersey: AUP.

Keren, M. (2010). Blogging and mass politics. Biography, 33(1), 110-126.

Koch, A. (2005). Cyber citizen or cyborg citizen: Baudrillard, political agency, and the commons in virtual politics. Journal of mass media ethics, 20(2\&3), 159-175. 
Komesu, F. (2010). Espaçios e fronteiras da "liberdade de express?o" em blogs na Internet". Trabalhos em Lingüistica Aplicada, Campinas, 49(2), 343-358.

Kleis, R. (2012). How newspapers began to blog: Recognizing the role of technologists in old media organizations' development of new media technologies. Information, communication $\mathcal{E}$ society. 15(6)

Kuntsman, A. (2010). Webs of hate in diaporic cyberspaces: The gaza war in the Russian-language blogosphere. Media, War $\mathcal{E}$ Conflict, 3(3), 299-313.

Kwasnik, B. Y Crowston, K. (2005). Introduction to the special issue: Genres of digital documents. Information technology E people, 18(2).

Landow, G. Hypertext 3,0: Critical theory and new media in the era of globalization. Maryland: John Hopkins University

Marcuschi, L. y Xavier, A. (2005). Hipertexto e Generos digitais: Novas formas de construcao de sentido. Rio de Janeiro: Lucerna.

Martin, J. R., y Rose, D. (2008). Genre relations: Mapping culture. London: Equinox.

Martin, J.R y White, P.R.R. (2005). The language of evaluation: Appraisal in English. London: PALGRAVE

Mayol, R. (2012). El derrumbe del modelo: La crisis de la economía de mercado en el Chile contemporáneo. Santiago, Chile: LOM.

Mitchell, D. (1995). The end of public space? People's park, definitions of the public, and democracy. Annals of the association of American geographers, 85(1), 108-133.

Moita Lopes, L. (2010). Os novos letramentos digitais como lugares de construçao de ativismo político sobre sexualidade e gênero. Trabalhos em Lingüística Aplicada, Campinas, 49(2), 393-417. 
Pinilla, R (2009). El lenguaje de los blogs. En R. Sarmiento y F. Vilches. La calidad del español en la red: Nuevos usos de la lengua en los medios digitales. Madrid: Ariel

San Martin, P. (2003). Hipertexto: Seis propuestas para este milenio. Buenos Aires: La crujía.

Santaella, L (2010). O novo estatuto do texto nos ambientes de hipermidia. En I. Signorini, (org.)[Re]Discutir texto, gênero e discurso. Sao Paulo: Parábola.

Smith, G. (2010). Blogging and the creative process. Journal of media Practice, 11(3), 281-287,

Swales, J. (1990). Genre analysis: English in academic and research settings. Cambridge: Cambridge University Press.

Swales, J. (2004). Research genres: Explorations and applications. Cambridge: Cambridge University Press

Toulmin, S. (1958). The uses of argument. Cambridge: Cambridge University Press.

Varela, J. (2005). El asalto a los medios sociales. Cuadernos de periodistas. Recuperado Agosto, 2, 2012, from http://www. apmadrid.es / Publicaciones / Libros / Relacion / Cuadernos/Numero_2/03.

Wei, L. (2009). Filter blogs vs. Personal journals: Understanding the knowledge production gap on the Internet. Journal of computer-mediated communication, 14, 532-558.

Woodly, D. (2008). New competencies in democratic communication? Blogs, agenda setting and political participation. Public Choices, 134 (1\&2), 109-123.

Yus, F. (2010). Ciberpragmática 2.0: Nuevos usos del lenguaje en Internet. Barcelona, España: Ariel. 